\title{
Research on Supply Chain Option Problems of Agricultural Products in the Perspective of Farmer-Supermarket Direct Purchase
}

\author{
Xiangfei Yang ${ }^{1}$, Zhongning $\mathrm{Fu}^{2, *}$ and Jinfang $\mathrm{Zhang}^{1}$ \\ ${ }^{1}$ School of Traffic and Transportation, Lanzhou Jiaotong University, Lanzhou, 730070, China; ${ }^{2}$ Antai College of Eco- \\ nomics \& Management, Shanghai Jiao Tong University, Shanghai, 200052, China
}

\begin{abstract}
In recent years, the rise of farmer-supermarket direct purchase is one of the innovative modes in agricultural supply chain operations, study its operation is very important for improving the operational efficiency of the agricultural supply chain. This paper based on the newsboy model and centralized decision-making model, established agricultural supply chain coordination model with option contract based on farmer-supermarket direct purchase, and analyzed the supply chain coordination conditions about the model, ultimately to achieve the maximize interests for farms, the specialty cooperative of peasants and supermarket. The $\mathrm{C}++$, MATLAB software and other methods were used to analyze and solve a concrete example.
\end{abstract}

Keywords: Agricultural products supply chain, farmer-supermarket direct purchase, option contract, supply chain coordination.

\section{INTRODUCTION}

Supply chain management as a new management philosophy, its main purpose is to manage and optimize enterprise's internal and external resources from a systematical viewpoint. In recent years, the thoughts, theories and methods of supply chain management extends to the agricultural sector. Besides the common supply chain characteristics as the agricultural supply chain has, its unique features include perishable, short life cycle, fresh etc, its determined the partner who involved in the agricultural supply chain undertake a higher risk, which attracted domestic and foreign scholars study the risk at different angles. Grimsdell (1996) by take agricultural supply chain of a British company as the research object, obtained the conditions in avoid supply chain risk and improve the agricultural supply chain operational efficiency [1]. Bendiksen, Dreyer (2003) by take fish supply chain in Norwegian as the research object, Gorton et al. (2006) by take dairy supply chain in Moldova as the research object, Clements et al. (2008) take fresh agricultural produce supply chain in New Zealand as the research object, studied on the conditions lead to risks in the agricultural supply chain operations and the solutions to avoid the risks at different angles [2-4]. Huang ZuHui et al. (2005), Chen Jun et al. (2009), Ling liuYi et al. (2013) by take agricultural supply chain of a China as the research object, studied on operational efficiency and risk of agricultural product supply chain from different perspectives [5-7].

Since 2008, in response to the price increase of agricultural products, continuing pressure on farmers to increase production without increasing income and food quality and safety issues, the Ministry of Commerce and the Ministry of
Agriculture in the country began to promote the farmersupermarket direct purchase. Farmer-supermarket direct purchase means a kind of cooperation mode between farmer and supermarket by intention agreement signed in advance. The supermarket purchases farm products directly from agricultural producers. It is not only an innovation for the distribution of agricultural products, but also an improvement for supply chain. It was put forward and pushed in by Chinese government from 2008, in order that the modern circulation mode can be introduced to vast countryside. They considered this new model can reduce the intermediate link of agricultural products circulation, guarantee the smooth sale of agricultural products, improve the quality and safety of agricultural products, and achieve the aspect which the supermarkets, farmers and consumers tripartite altogether wins [8].

December 2008, the Ministry of Commerce and Ministry of Agriculture jointly issued the document about The Notice of Attempting to Launch Farmer-supermarket Direct Purchase, deploy to the operation of farmer-supermarket direct purchase. The notice proposed farmer-supermarket direct purchase is an effective way to reduce the circulation links and distribution costs of agricultural products, it is the fundamental way to solve the difficulty in selling fresh produce, and it have important practical significance to build a modern circulation system of agricultural products, increase the income of farmers and promote the coordinated development of urban and rural areas. By 2012, the proportion of direct procurement of fresh agricultural products for the pilot enterprises should more than $50 \%$, reduction the agricultural product flow-stages and distribution costs, at the same time, building the cold chain system of fresh agricultural products from the origin to the consume. In addition, the notice also stated that the supermarkets + cooperatives + farmers mode is the main mode of the current farmer-supermarket direct purchase. Therefore, it should let supermarkets as the main relation object for famer and the specialty cooperative of 
peasants when choose the project implementation body. Since then, according to local business conditions recommended, the Ministry of Commerce and Ministry of Agriculture determined the Wal-Mart, Carrefour, Metro, JiaJiaYue and other five supermarkets as the first batch of pilot enterprises, till then, farmer-supermarket direct purchase as a way of innovation for agricultural product circulation, officially entered the field of agricultural products circulation in china [9].

\section{THE ADVANTAGE OF FARMER-SUPERMARKTE DIRECT PURCHASE CAMPARE TO TRADITINAOL AGRICULTURAL CIRCULATION}

In the traditional trading patterns, circulation of agricultural products through multi-level brokers, wholesalers, wholesale, supply companies, etc. Excessive circulation links resulted increased distribution costs and vast losses, meanwhile, it lead to the product quality management cannot be implemented retroactively. The unidirectional transfer of agricultural information causes information lag, information distortion and so on. It can be seen that there are a lot of obstacles existed in logistics and information flow in traditional agricultural circulation, it hampered the development of agricultural product in china. The appearance of farmersupermarket direct purchase can be regarded as a highly efficient system of agricultural circulation to replace inefficient traditional circulation patterns, farmer-supermarket direct purchase has many advantages than traditional circulation patterns. Zhang ShiQing and Li ShuHua (2010) discussed the household level, they research conclusion illustrate farmer-supermarket direct purchase can solve the problem of product sales, avoiding market risk arising from information asymmetry, and increase the income of farmers [10]. Ma FengQi (2010) analyzes the impact of various aspects of the farmer-supermarket direct purchase for supermarket, the implementation of farmer-supermarket direct purchase can ensure product safety, improve product freshness, enhance the competitiveness of the supermarket [11]. Song Chao and Li ShuGuang (2010) summarized the effect of farmersupermarket direct purchase for the various stakeholders, including the facilitator namely government, leader namely supermarket, implementer namely various types of agricultural cooperative organizations and leading enterprises, supporters namely modern logistics, the direct beneficiaries namely Farmers and consumers [9]. Concretely speaking, the farmer-supermarket direct purchase compared to traditional agricultural products circulation, its advantage reflected in the following aspects [12]:

(1) The farmer-supermarket direct purchase is beneficial to expand markets for agricultural products.

The farmer-supermarket direct purchase is beneficial to establishment a stable purchase and sale relationship between farmers and retailers to promote the sales of agricultural products. According to the Ministry of Commerce survey, $66 \%$ of farmers believe that the current sales channels in agricultural exist instability, $35 \%$ of farmers hope through the contract to sale agricultural products, $27 \%$ of farmers hope through the enterprises to sale agricultural products [14]. Development farmer-supermarket direct purchase to enhance supermarket and agricultural producers oriented to market demand, according to the terms of the contract, on the basis of mutual benefits of agriculture and commerce, it is meaningful to establish closer relations among the participators in farmer-supermarket direct purchase. On the one hand, farmer-supermarket direct purchase can stabilize the agricultural marketing channels and solve the problem about the non-convergence of information between agricultural production and marketing, it can enable farmers to avoid market risks effectively and focus on agricultural production. On the other hand, farmer-supermarket direct purchase enable the supermarkets to get a stable, reliable quality, health and safety supply of agricultural products and focus on the sales of agricultural products.

(2) The farmer-supermarket direct purchase is beneficial to obtain higher selling prices of agricultural products

The farmer-supermarket direct purchase is beneficial to reduce the cost of agricultural products circulation, helpful to farmers and consumers. Because the logistics facilities in low level for long term in china, the trade of agricultural products need a long time, high cost, loss, low efficiency. Development farmer-supermarket direct purchase can effectively reduce the circulation links, meanwhile, it can promote social logistics, especially third-party logistics, including cold chain logistics development and utilization, the formation of packaging, sorting, processing, distribution, the huge logistics network, and promote the circulation efficiency of agricultural products. Farmer-supermarket direct purchase can save $20 \%$ to $30 \%$ of the purchase cost to supermarket, so the supermarket can increase the purchase price of agricultural products and decrease the selling price of agricultural products to consumers.

(3) The farmer-supermarket direct purchase is beneficial to expand the scale of the specialty cooperative of peasants.

The specialty cooperative of peasants which participate in the farmer-supermarket direct purchase can achieve sustainable market demand for agricultural products, and the sale price is higher than the market price of similar products, the benefit-sharing mechanisms can attract dispersed farmers to participate in the specialty cooperative of peasants, therefore it expand the scale of the specialty cooperative of peasants

(4) The farmer-supermarket direct purchase is beneficial to improve the quality and safety of agricultural products

Generally, supermarkets make food safety testing to planting base of agricultural products before signing a procurement contract with the specialty cooperative of peasants, each batch of agricultural products will be subject to random testing before entering the supermarket stores. These stringent requirements are beneficial to promote the specialty cooperative of peasants to improve the quality and safety of agricultural products. The biggest difference between the farmer-supermarket direct purchase and the traditional agricultural products distribution mode is that the supermarket directly involved in the monitoring and management of agricultural production process. Supermarkets raise claims for agricultural products according to the safety standards of food hygiene and quality, farmers produce the agricultural products in accordance with the requirements of supermarkets, supermarkets and the specialty cooperative of peasants 
provide technical guidance, and provide a unified seeds, pesticides, fertilizers and other production materials to ensure the quality of agricultural products.

(5) The farmer-supermarket direct purchase is beneficial to improve the modern management and organizational skills of the specialty cooperative of peasants

After the implementation of the farmer-supermarket direct purchase, the specialty cooperative of peasants can learn and introduction of modern management mode and experience when in cooperation with the supermarket, thus contributing to the rapid increase in their modern management and organizational skills

(6) The farmer-supermarket direct purchase is beneficial to promote the use of advanced equipment

Based on the assurance of agricultural product quality, not only the supermarkets tend to investment equipments to the specialty cooperative of peasants and cooperative farmers, but also the specialty cooperative of peasants need investment equipments to strengthen the following stage of agricultural products circulation, including packaging, storage and transportation, which can promote the use of advanced equipment

(7) The farmer-supermarket direct purchase is beneficial to change the traditional production consciousness

The need of information of market demand for agricultural products in traditional agricultural production is poorly understood, after the implementation of the farmersupermarket direct purchase, the supermarket can collect and analyze customers' information and sale information to provide basis for decision choices in the product supply chain. Therefore, the information about supply and demand quantity and price contracts offered by supermarkets which participated in the farmer-supermarket direct purchase helps to avoid the blindness of farmers to produce, prompting producers in a timely manner to respond to market needs, reduce the waste of resources

(8) The farmer-supermarket direct purchase is beneficial to increase the income of farmers

Development the farmer-supermarket direct purchase will help increase employment of farmers in agricultural production, the specialty cooperative of peasants, the transportation and warehousing of agricultural products and other aspects. after achieving institutional innovation of farmersupermarket direct purchase, it is able to solve marketing, financial and technical issues through organizational strength, to reduce individual risk, guarantee quality, cost savings through intensive production, which can lead to revenue growth and increase income of farmers and expand rural consumption.

(9) The farmer-supermarket direct purchase is beneficial to establish brand image of agricultural products and improve its market competitiveness

In the traditional agricultural products production mode, different villages, different farmers use different seeds and fertilizer, the products quality and specifications of the agricultural products which produced are also different, it is difficult to form a brand and to sell a high price. In the farmer- supermarket direct purchase mode, the supermarket guide farmers for production according to consumer demand, not only variety, but also in quality assurance, so, it is easy to form a market of its own brand.

Above all, the rise and development for farmersupermarket direct purchase pattern provided a new market for agricultural products, but with the new pattern's development, the agricultural supply chain operations exposed some problems that include unclear bearing on responsibility, unreasonable distribution of profits, lack of effective supervision, etc, which prevented the further development of farmer-supermarket direct purchase. Options contracts as effective tool to hedge supply chain risk (including demand, supply and price risk), is becoming popularity in supply chain management [13]. The paper based the perspective of farmer-supermarket direct purchase, select the agricultural supply chain as the research object, combined with the option game, study on the risk of agricultural supply chains.

\section{COORDINATION MODEL OF AGRICULTURAL PRODUCTS SUPPLY CHAIN WITH OPTION CON- TRACTS BASED ON FARMER-SUPERMARKET DI- RECT PURCHASE}

\subsection{Model Description}

Under the perspective of farmer-supermarket direct purchase, analysis of the assumption in the two -stage agricultural supply chain, which composed of supermarket and the specialty cooperative of peasants. The specialty cooperative of peasants organizes the farmers to produce and sell an agricultural product which has the long production cycle and short sales cycle $[14,15]$. The loss of supermarket and the specialty cooperative of peasants caused by stockout is different during the agricultural product sales. After the busy season for agricultural product sales, the salvage value for remaining units of the agricultural product for supermarket and the specialty cooperative of peasants is also different which is due to their different role in the supply chain. This article assumes that does not consider the cost of sales for the supermarket.

\subsubsection{Symbol Definitions and Descriptions}

$r$ : Unit retail prices of agricultural product for supermarket;

$w$ : Unit wholesale prices of agricultural product for supermarket;

$v_{r}$ : Unit salvages value of remaining agricultural product for supermarket;

$v_{s}$ : Unit salvages value of remaining agricultural product for the specialty cooperative of peasants;

$c$ : Unit production cost of agricultural product for farmer;

$c_{o}$ : Unit purchase option price of agricultural product;

$c_{e}$ : Unit exercise option price of agricultural product;

$M:$ Purchase quantity of option for supermarket; 
$Q$ : Order quantity of agricultural product by supermarket;

$S(Q)$ : Expectation sale quantity of agricultural product for supermarket;

$I(Q)$ : Expectation inventory of agricultural product for supermarket;

$L(Q)$ : Expectation stockout of agricultural product for supermarket;

$K$ : Total yield of agricultural product before exercise option;

$P_{r}$ : Unit loss caused by stockout for supermarket;

$D$ : Market demand of customers for agricultural product;

$P_{S}$ : Unit loss caused by stockout for the specialty cooperative of peasants;

$x$ : Real demand for agricultural product;

$F(\mathrm{X})$ : Distribution function of $\mathrm{D}$, differentiable and continuity increasing;

$u$ : Mean of market demand D;

$f(\mathrm{x})$ : Probability density function of $\mathrm{D}$, differentiable and reversible.

\subsubsection{Research Hypothesis}

Assume the following relationship between the parameters:

$v_{s} \leq c \leq w \leq r$, and $v_{r} \leq c_{e}, v_{s} \leq c_{e}$, to ensure that the profits of supermarkets and the specialty cooperative of peasants;

$w \leq c_{0}+c_{e}$, to ensure supermarket can obtain supply elastic and incentive supermarket take wholesale price when using option;

$c{ }_{0} \leq w-v_{r}$, to incentive supermarket take option price;

$c_{0}+c_{e} \leq r+p_{r}$, to ensure option is more attraction for supermarket than spot market.

\subsection{Newsboy Model without Option Contract}

Research agricultural supply chain problems in the case of without option, the supermarket only has one chance to order agricultural product.

The expected profit for the supermarket is:

$$
\begin{aligned}
& \prod_{r}^{N}=r S(Q)+v_{r} I(Q)-w Q-p_{r} L(Q) \\
& =\left(r+p_{r}-w\right) Q-\left(r+p_{r}-v_{r}\right) \int_{0}^{Q} F(x) d x-p_{r} \mu
\end{aligned}
$$

The expected profit for the specialty cooperative of peasants is:

$$
\begin{aligned}
& \prod_{s}^{N}=w Q+v_{s}(K-Q)-c Q-p_{s} L(Q) \\
& =\left(w+p_{s}-c-v_{s}\right) Q+v_{s} K-p_{s}\left[\mu+\int_{0}^{Q} F(x) d x\right]
\end{aligned}
$$

The total profit for agricultural supply chain is:

$$
\begin{aligned}
& \prod_{N}=\prod_{r}^{N}+\prod_{s}^{N}=\left(r+p_{r}+p_{s}-c-v_{s}\right) Q- \\
& \left(r+p_{r}+p_{s}-v_{r}\right) \int_{0}^{Q} F(x) d x+v_{s} K-\left(p_{r}+p_{s}\right) \mu
\end{aligned}
$$

The Economic order quantity for supermarket is:

$$
Q_{N}=F^{-1}\left(\frac{r+p_{r}+p_{s}-c-v_{s}}{r+p_{r}+p_{s}-v_{r}}\right)
$$

\subsection{Centralized Decision-making Model with Option Contract}

In order to comparative analysis, introducing centralized decision-making mode with option contract on the basis of newsboy model without option contract. The centralized decision-making mode takes the supply chain as a whole, it can maximum the whole profit when make optimal decision analysis to it. In the centralized decision-making model, the total profit of agricultural supply chain can be expressed as:

$$
\begin{aligned}
& \prod_{M}=r S(Q+M)+v_{r} I(Q)+v_{s}[I(Q+M)-I(Q)- \\
& c(Q+M)-\left(p_{r}+p_{s}\right) L(Q+M) \\
& =\left(r+p_{r}+p_{s}-c\right)(Q+M)-\left(r+p_{r}+p_{s}-v_{s}\right) \int_{0}^{Q+M} F(x) d x+(5) \\
& \left(v_{r}-v_{s}\right) \int_{0}^{Q} F(x) d x-\left(p_{r}+p_{s}\right) \mu
\end{aligned}
$$

The Economic order quantity for supermarket is:

$$
Q_{M}=F^{-1}\left(\frac{r+p_{r}+p_{s}-c}{r+p_{r}+p_{s}-v}\right)
$$

wherein, $v=\max \left(v_{r} \notin \boldsymbol{v}_{s}\right)$, comparing formula(4) and formula (6), apparently $Q_{M}>Q_{N}$.It suggested that the EOQ for supermarket in centralized decision model when introduced the option contract is higher than the EOQ in the newsboy model.

\subsection{Agricultural Supply Chain Coordination Model with Option Contract Based on Farmer-Supermarket Direct Purchase}

\subsubsection{Agricultural Supply Chain Coordination Model with Option Contract}

The supermarket and the specialty cooperative of peasants in agricultural supply chain established an information sharing partnership by contract option which in order to maximize benefits.

The expected profit for supermarket is:

$$
\begin{aligned}
& \prod_{A}=r S(Q+M)+v_{r} I(Q)-w Q-p_{r} L(Q+M)- \\
& c_{0} M-c_{e}\left[(D-Q)^{+}-(D-Q-M)^{+}\right] \\
& =\left(c_{e}-r-p_{r}\right) \int_{0}^{Q+M} F(x) d x+\left(v_{r}-c_{e}\right) \int_{0}^{Q} F(x) d x+ \\
& \left(r+p_{r}-w\right) Q+\left(r+p_{r}-c_{0}-c_{e}\right) M-p_{r} \mu
\end{aligned}
$$


The expected profit for the specialty cooperative of peasants is:

$$
\begin{aligned}
& \prod_{B}=w Q+c_{0} M+c_{e} \min \left[(D-Q)^{+} \in-M\right]+ \\
& v_{s}\left[M-(D-Q)^{+}\right]^{+}-c(Q+M)-p_{s} L(Q+M) \\
& =\left(v_{s}-p_{s}-c_{e}\right) \int_{0}^{Q+M} F(x) d x+\left(c_{e}-v_{s}\right) \int_{0}^{Q} F(x) d x+ \\
& \left(w+p_{s}-c\right) Q+\left(c_{0}+c_{e}+p_{s}-c\right) M-p_{s} \mu
\end{aligned}
$$

The EOQ and optimal purchase quantity of option for supermarket based on option contract coordination model is respectively $Q_{A}$ and $M_{A}$ :

$Q_{A}=F^{-1}\left(\frac{w-c_{0}-c_{e}}{v_{r}-c_{e}}\right)$

$M_{A}=F^{-1}\left(\frac{r+p_{r}-c_{0}-c_{e}}{r+p_{r}-c_{e}}\right)-Q_{A}$

The total profit for agricultural supply chain is:

$\prod_{C}=\prod_{A}+\prod_{B}$

$=\left(v_{s}-r-p_{r}-p_{s}\right) \int_{0}^{Q+M} F(x) d x+\left(v_{r}-v_{s}\right) \int_{0}^{Q} F(x) d x+$

$\left(r+p_{r}+p_{s}-c\right)(Q+M)-\left(p_{r}+p_{s}\right) \mu$

The EOQ for agricultural supply chain is:

$(Q+M)_{A}=F^{-1}\left(\frac{r+p_{r}+p_{s}-c}{r+p_{r}+p_{s}-v_{s}}\right)$

\subsubsection{Research on Option Parameters}

(1) The relationship between $c_{0}$ and $c_{e}$

In order to achieve the coordination for supply chain, the EOQ for the whole supply chain should equal to the sum for the EOQ of agricultural products and Purchase quantity of option based on option contract model, it means formula (12) is equal to the sum of equation (9) and (10). then it can get:

$c_{0}=\frac{c-v_{s}}{r+p_{r}+p_{s}-v_{s}} \cdot\left(r+p_{r}-c_{e}\right)$

(2) The relationship between $v_{s}$ and $v_{r}$

In order to achieve the coordination for supply chain, the EOQ based on centralized decision-making model should equal to the EOQ base on the coordination model with option contract, that is formula (6) equal to formula (12), than, it can attain $v_{s} \geq v_{r}$.

(3) The determination for profit distribution parameters $\theta$

According to formula (7) and formula (11), assume:

$$
\prod_{A}=\theta \prod_{C} \text { Then } \prod_{B}=(1-\theta) \prod_{C}
$$

It can be deduced that:

$\theta=1-\frac{c_{e}-v_{s}}{r-v_{s}}$

According to the above assumes, it can attain $0 \leq \theta \leq 1$. We can known the distribute profit for supermarket and the specialty cooperative of peasants basis for $\theta$.

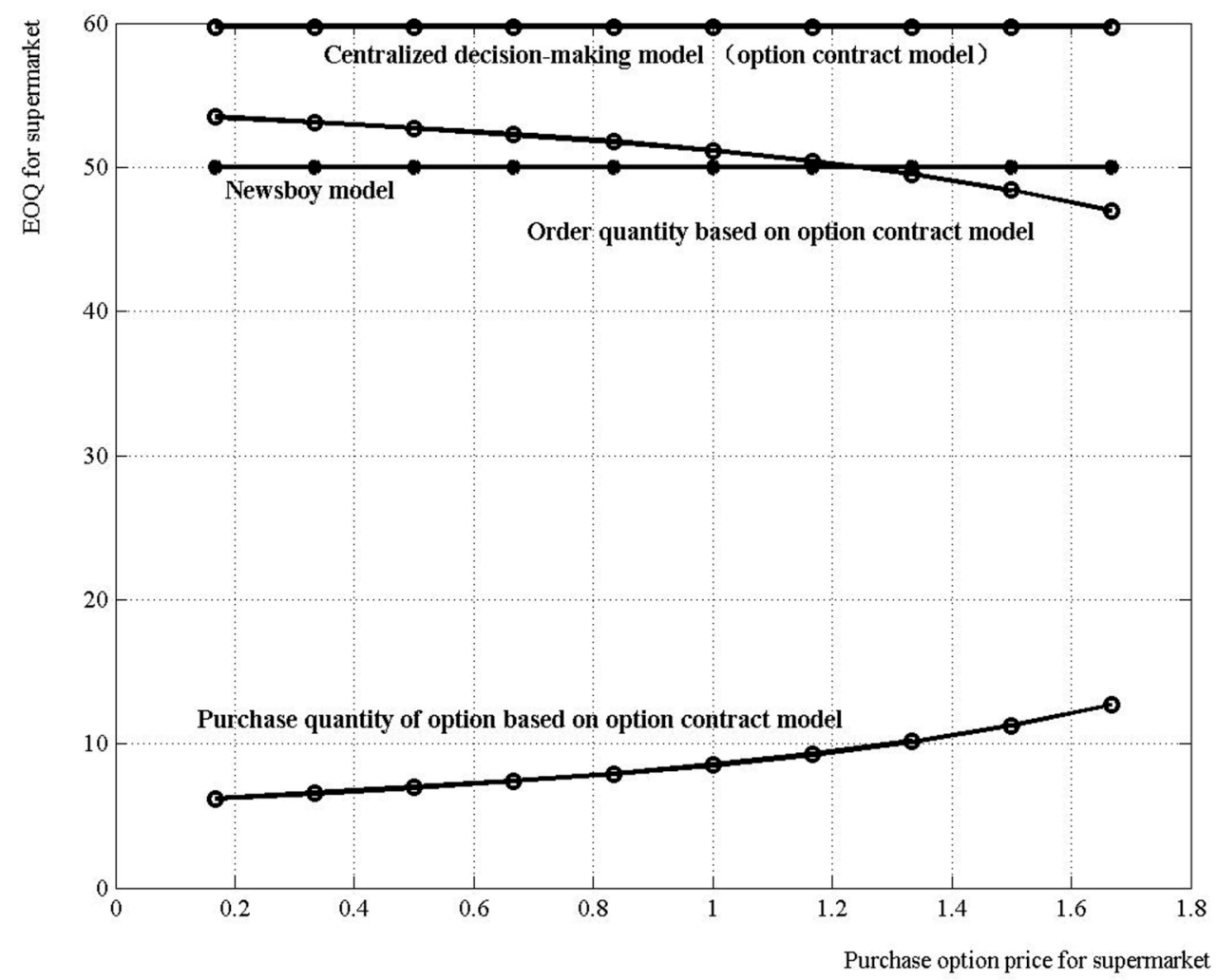

Fig (1). EOQ of the three models. 


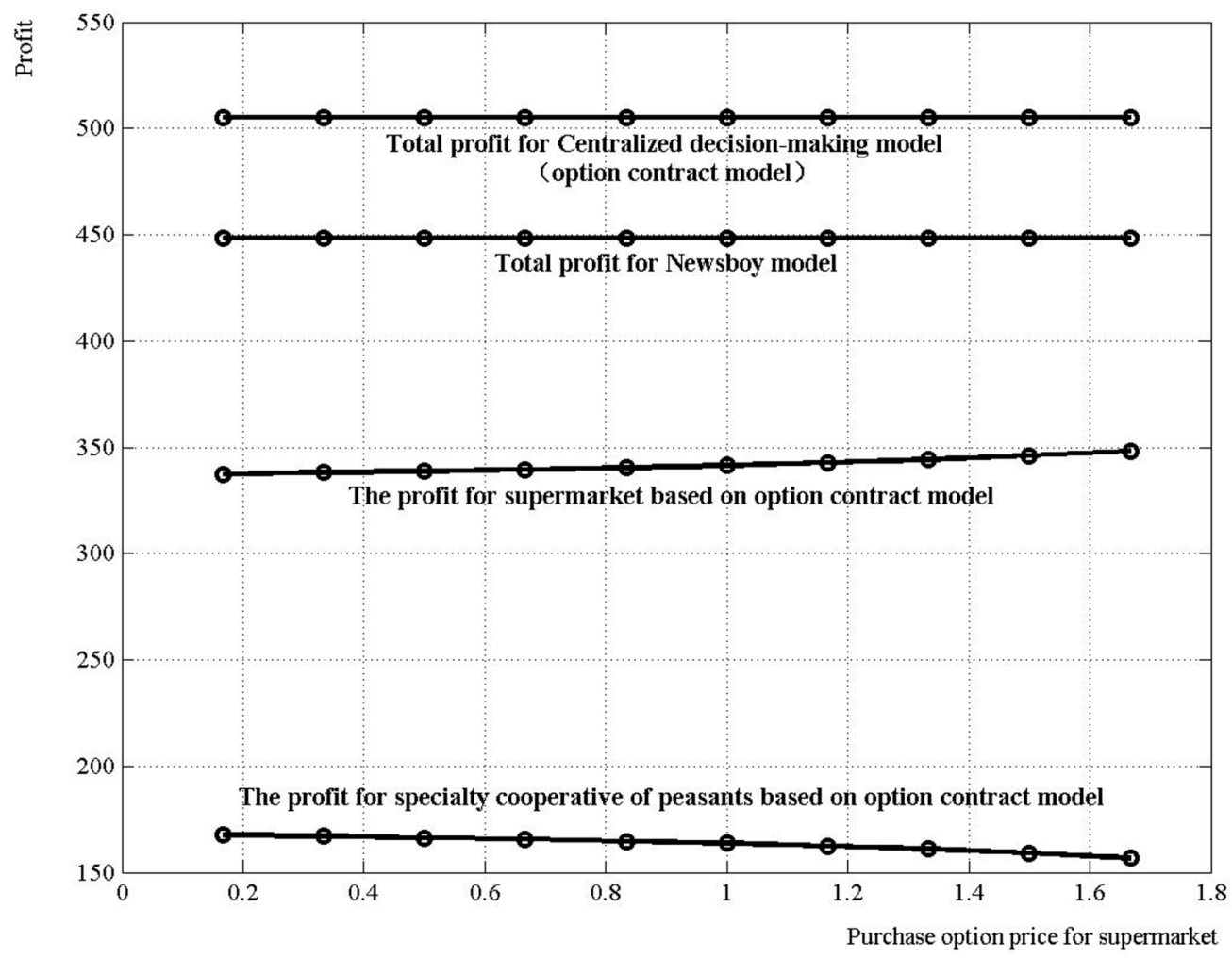

Fig (2). Profits of the three models.

\subsection{Analysis of Examples}

\subsubsection{The Study on Supply Chain Coordination When the Salvage Value is Equal}

Assuming that the probability density function (pdf) of market demand $f(x)$ for a farm $\mathrm{D}$ obey normal distribution in $\mu=50 £-\sigma=10$. Assuming other related parameters is: $K=45 \mathrm{~kg}, \quad r=20 \mathrm{Yuan} / \mathrm{kg}, \quad w=12 \quad$ Yuan $/ \mathrm{kg}, \quad c=9$ Yuan $/ \mathrm{kg}, \quad v_{s}=v_{r}=6 \quad$ Yuan $/ \mathrm{kg}, \quad p_{r}=3 \quad$ Yuan $/ \mathrm{kg}, \quad p_{s}=1$ Yuan $/ \mathrm{kg}$, the value range of $c_{e}$ is $13 \sim 22$ yuan $/ \mathrm{kg}$. By formula (13), and use NORMINV function in Excel of equation (4), (6), (9) and (10) to calculate the EOQ of the three models, use Matlab to plot, as shown in Fig. (1). By formula (3), (5) and (11), solved by the $\mathrm{C}++$ programming and NORMDIST function in Excel to calculate profits of the three models, use Matlab to plot, as shown in Fig. (2).

\subsubsection{The Study on Supply Chain Coordination When the Salvage Value is not Equal}

Assuming $v_{s}=6 \mathrm{Yuan} / \mathrm{kg}, v_{r}=2 \mathrm{Yuan} / \mathrm{kg}$, The other hypotheses are the same as 2.5.1. To calculate the total profits for supply chain of the three models, use Matlab to plot, as shown in Fig. (3).

It can be obtained from Fig. (1), the EOQ in centralized decision-making model is equal to the EOQ in option contract model, and the sum of order quality and purchase quantity of option based on option contract model is equal to the total order quality of supply chain in option contract model, then agricultural supply chains achieve coordination. It can be obtained from Fig. (2), the sum of the profit for specialty cooperative of peasants and the profit for supermarket based on option contract model is equal to the total profit for supply chain in option contract model, it means the supermarkets and the specialty cooperative of peasants can make any profit distribution, and the total profit for supply chain in centralized decision-making model is equal to the total profit for supply chain in option contract model, therefore the agricultural supply chains achieve coordination.

It can be obtained from Fig. (3), the total profit for supply chain in option contract model is not equal to the total profit for supply chain in centralized decision-making model, therefore the agricultural supply chains has not achieve coordination.

So it can be concluded that the agricultural supply chains achieve coordination when unit salvages value of remaining agricultural product for supermarket is equal to unit salvages value of remaining agricultural product for the specialty cooperative of peasants.

\section{CONCLUSION}

This paper established models based on relevant assumptions, studied three models which include newsboy model without option contract, centralized decision-making model with option contract and agricultural supply chain coordination model with option contract based on farmersupermarket direct purchase, if it aim at total supply chain profits, the profit for specialty cooperative of peasants and the profit for supermarket as a model for the optimal metrics, 


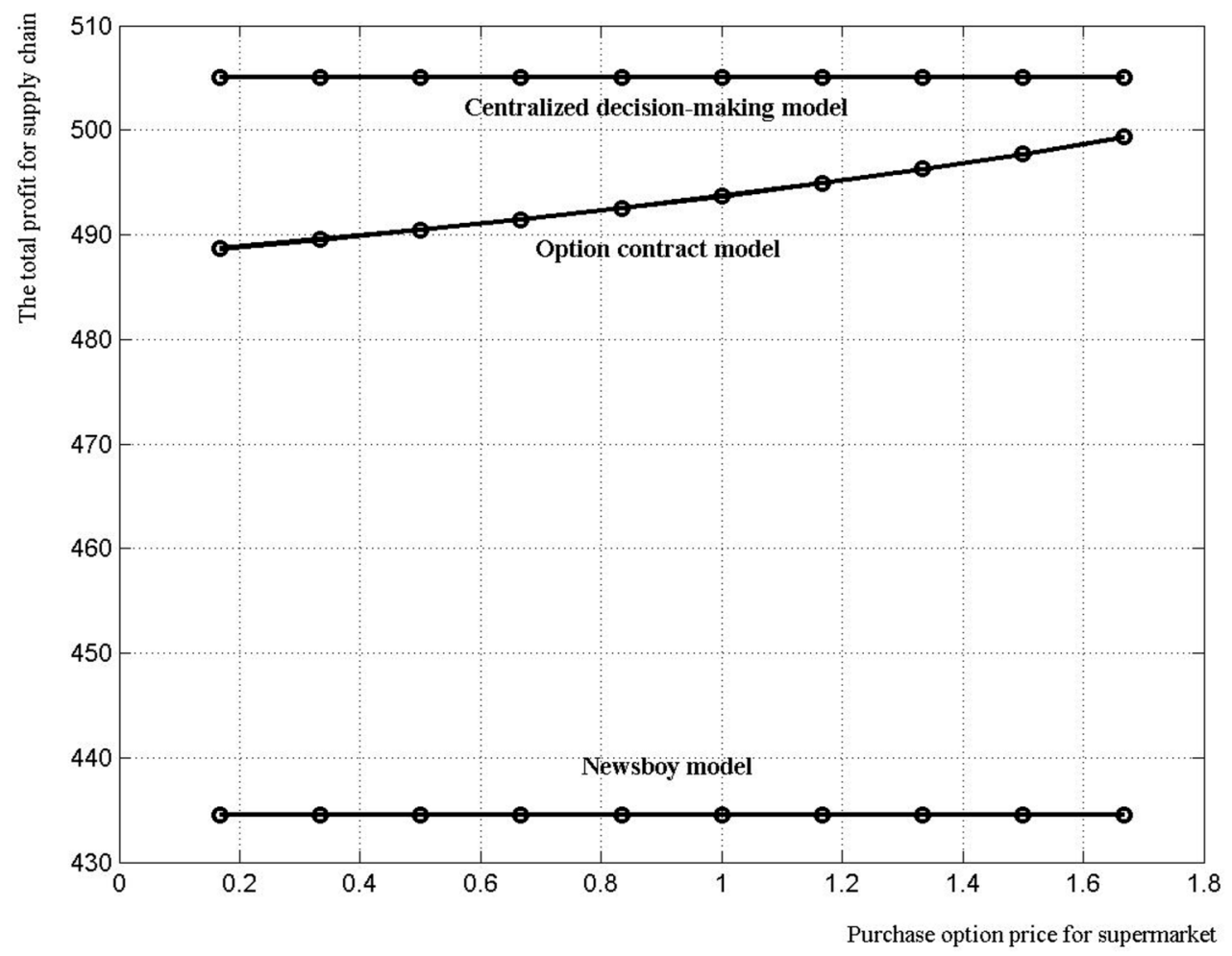

Fig (3). Total profits for supply chain of the three models.

it can be found agricultural supply chain coordination model with option contract based on farmer-supermarket direct purchase has an absolute advantage. By analysis of examples, it can be known when unit salvages value of remaining agricultural product for supermarket is equal to unit salvages value of remaining agricultural product for the specialty cooperative of peasants, the agricultural supply chains achieve coordination.

\section{CONFLICT OF INTEREST}

The authors confirm that this article content has no conflict of interest.

\section{ACKNOWLEDGEMENTS}

This paper belongs to the project of the "Research Foundation for Yong Scholars of Lanzhou JiaoTong University, No. 2013035; The Study on Application of Option Game On Fresh Agricultural Products in the Perspective of FarmerSupermarket Direct Pruchase. This paper belongs to the project of the "Higher Education Scientific Research Project Foundation of Gansu Provincial Education Department", No.2013A-056; The study on coordination development mechanism between rural labor transfer of Gansu province and "liancunlianhu" construction. This paper also belongs to the project of the "Higher Education Scientific Research Project Foundation of Gansu Provincial Education Department", No.2013A-053; "The Behavior Subject Analysis and Control Strategy Simulation of Road Freight Market”.

\section{REFERENCES}

[1] K.Grimsdell, "The supply chain for fresh vegetables: what it takes to make it work,"Supply Chain Management: An International Journal, vol. 1, pp. 11-14, January 1996.
[2] B.I. Bendiksen and B. Dreyer, "Technological changes- the impact on the raw material flow and production," European Journal of Operational Research, vol. 144, pp. 237-246, February 2003.

[3] M. Gorton, M. Dumitrashko and J. White, "Overcoming supply chain failure in the agri-food sector: A case study from Moldova," Food Policy, vol. 31, pp. 90-103, January 2006.

[4] M.D. Clements, R.M. Lazo and S.K. Martin, "Relationship connectors in NZ fresh produce supply chains," British Food Journal, vol. 110, pp. 346-360, October 2008.

[5] Z.H. Huang, B.X. Lu and D.Y. Liu, "An Exposition of Dealing in Fresh Product and Supply Chain Management in Chinese Supermarket," Business Economics and Administration, vol. 159, pp. 913, January 2005.

[6] J. Chen and B. Dan, "Fresh agricultural product supply chain coordination under the physical loss-controlling,"Systems Engineering-Theory \& Practice, vol. 29, pp. 54-62, March 2009.

[7] L.Y. Lin, X.L. Guo, Z.J. Hu and L. Liang, "The risk-sharing contracts under random yield and stochastic demand in agricultural supply chain, "Chinese Journal of Management Science, vol. 21, pp. 50-57, April 2003.

[8] X.Y. Han, "Fresh agricultural products logistics under "farmersupermarket direct-purchase': problem and suggestions analysis," Applied Mechanics and Materials. vol. 97-98, pp. 1046-1049, September 2011.

[9] C. Song and S.G. Li, "Analysis of the practice of straight-tosupermarket distribution of agricultural products," Logistics Technology, vol. 29, pp. 28-30, May 2010.

[10] S.Q. Zhang and S.H. Li. "Promoting agricultural development through modern retail value chain - opportunities arising from direct farming-supermarket connection,"Journal of Nanjing University of Science and Technology, vol.23, pp. 10-58, August 2003.

[11] F.Q. Ma, "Discussion on the impact of alliance of agricultural and supermarkets on supermarkets and its counter measures," Journal of Anhui Agricultural Science. vol. 38, pp. 4959-4960, September 2010.

[12] D.H. Hu, W.M. Yang and Y. Zhang, "Farmer-supermarket direct purchase and the development of the specialty cooperative of 
peasants",Issuesin Agricultural Economy vol. 27, pp.12-14,August 2009.

[13] Z.Fu, Z.Juan, and R.Peng, "Study on interest allocation method of joint distribution," Int. J. Serv. Oper. Inf., vol. 4, pp. 97-106, September 2009.

[14] W.Wang, Z.N.Fu, Y.N.Li and L.Z. Zhang,"Study on contract based coordination of perishable produce supply chains based on retailer promotion",Logistics Technology, vol.33, pp.252-254, January 2014

[15] Y.K.Wang and W.S.Li, "Study of supply chain collaboration pattern on farmer-supermarket direct supply,"Journal of Southwest University for Nationalities.Natural Science Edition. vol. 38, pp.119-123,January 2012.

Received: September 16, 2014

Revised: December 23, 2014

Accepted: December 31, 2014

(C) Yang et al.; Licensee Bentham Open.

This is an open access article licensed under the terms of the Creative Commons Attribution Non-Commercial License (http://creativecommons.org/licenses/by-nc/3.0/) which permits unrestricted, non-commercial use, distribution and reproduction in any medium, provided the work is properly cited. 